\title{
Active Case Finding of Pulmonary Tuberculosis among Prison Inmates in Aba Federal Prison, Abia State, Nigeria
}

\author{
Emmanuel O. Ekundayo ${ }^{*}$, Okorie Onuka², Gidado Mustapha ${ }^{3}$, Mazi Geoffrey ${ }^{4}$ \\ ${ }^{1}$ Centre for Molecular Biosciences and Biotechnology, Infectious Diseases and Public Health Unit, Michael \\ Okpara University of Agriculture, Umudike, Nigeria \\ ${ }^{2}$ State Tuberculosis Control Programme, Public Health Department, Ministry of Health, Umuahia, Nigeria \\ ${ }^{3}$ KNCV, TB Care 1, Abuja, Nigeria \\ ${ }^{4}$ Nigerian Prisons Services, Aba Federal Prison, Aba, Nigeria \\ Email: ${ }^{*}$ ekundayo.emmanuel@mouau.edu.ng
}

Received 15 February 2015; accepted 2 March 2015; published 5 March 2015

Copyright (C) 2015 by authors and Scientific Research Publishing Inc.

This work is licensed under the Creative Commons Attribution International License (CC BY).

http://creativecommons.org/licenses/by/4.0/

c) (i) Open Access

\section{Abstract}

Background: Conditions in prisons favour rapid transmission of Mycobacterium tuberculosis and progression to tuberculosis (TB) disease, resulting in higher prevalence rates of TB in prisons than in the corresponding general population. However, in many developing countries with high TB burden, passive case-finding remains the usual approach to case detection of TB in prisons. On this premise, the Abia State TB Control Programme conducted a pilot study to assess the contribution of active case finding to tuberculosis control in Aba Federal Prison. Methods: The inmates were clinically screened and those with symptoms suggestive of TB cases were tested by sputum smear microscopy. Results: Out of the total number of 477 prison inmates present in the prison at the time of study, $449(94.1 \%)$ were clinically screened for history of cough of 2 weeks' duration; $52(10.42 \%)$ met the inclusion criteria for sputum smear microscopy. Eleven of the $52(21.15 \%)$ tested for acid fast bacilli (AFB) by direct smear light microscopy were positive for AFB. One inmate was on anti-tuberculosis therapy; this with the 11 cases detected in the course of this study gave a total of 12 inmates of Aba prison with active pulmonary tuberculosis at the time of this study. This gives a minimum point prevalence rate of 2405 cases per 100,000 prison inmates. Four of the 11 prison cells had at least one smear positive case with 7 of the 11 cases concentrated in two cells. The age group of 25 - 34 years had the highest number of sputum positive cases. Conclusion: Active case-finding resulted in detection of 11 new cases of sputum positive tuberculosis (an increase in detection rate of $1100 \%$ ) and the prevalence of sputum positive TB is very high (2405 cases per 100,000 prison inmates) in Aba prison. There is an urgent need to institute more effective TB case-finding and control in the prison.

\footnotetext{
*Corresponding author.
}

How to cite this paper: Ekundayo, E.O., Onuka, O., Mustapha, G. and Geoffrey, M. (2015) Active Case Finding of Pulmonary Tuberculosis among Prison Inmates in Aba Federal Prison, Abia State, Nigeria. Advances in Infectious Diseases, 5, 57-62. http://dx.doi.org/10.4236/aid.2015.51006 


\section{Keywords}

\section{Pulmonary Tuberculosis, Prisons Inmates, Active Case-Finding, Sputum Smear Microscopy}

\section{Introduction}

Tuberculosis (TB) is an infectious bacterial disease caused by Mycobacterium tuberculosis complex. It is spread through the air when people who have an active TB disease cough, sneeze, or otherwise spread aerosol of respiratory fluids through the air. Prisons are often high-risk environments for TB transmission because of severe overcrowding, poor nutrition, poor ventilation, and limited access to often insufficient health care. Moreover, prisoners are overwhelmingly male, are typically aged 15 - 45 years, and come predominantly from poorly educated and socioeconomically deprived sectors of the population where TB infection and transmission are higher [1]. One infectious prisoner with TB may infect the others very efficiently. The combination of overcrowding, poor nutrition, poor ventilation and lack of screening for TB has turned prisons into breeding grounds and incubators for TB.

High prevalence rates of TB in prisons of developing countries have been reported by others. Lawal et al. [2] reported a high prevalence of TB in Kuje Prisons in the Federal Capital Territory, Abuja, Nigeria. Noeske et al. [3] reported a point prevalence rate of 3.5\% in Cameroon and Rao [4] reported a prevalence of active TB in jail population in Karachi of 3.75 times higher than general population. In Bangladesh, Banu et al. [1] found a prevalence of $13.5 \%$ in Dhaka Central Jail. This present study was conducted to assess the prevalence of TB and the contribution of active case finding to tuberculosis control in Aba Federal Prison in Abia State, Nigeria.

\section{Materials and Methods}

\subsection{Study Setting}

Aba Federal Prison, a medium security penitentiary facility located in Aba, a densely populated major commercial city of Abia State in the South Eastern Nigeria was built in the early 1920s, to accommodate a maximum capacity of 500 prison inmates. As a provincial prison, it accommodates all classes of prisoners except the condemned criminals. The total number of inmates was 477 at the time of this study (September-October, 2013). The prisoners were accommodated in 7 wards consisting of 11 cells numbered C, D, E wards and G ward cell 1 and 2, $\mathrm{H}$ ward cell 1 and 2 and I ward cell 1-3 and a Female ward. Although not crowded at the time of study, the living and sanitary conditions were not different from those in most Prisons in developing countries [5].

The prison has a Medical Department, staffed by one medical doctor and other cadre of health personnel. Cases of Tuberculosis (TB) in the prison are usually identified through passive case-finding. Inmates who present symptoms suggestive of TB are referred to either one of two directly observed treatment short course (DOTS) Centres at the Infectious Disease Hospital (IDH) Aba or the Aba South Local Government TB Microscopy Laboratory.

\subsection{Study Participants and Methods}

With consent of the prison authority, a staff of the medical department assisted by a prison guard informed the prison inmates about the study. The inmates were clinically screened for symptoms of TB and those with current episode of cough lasting for two or more weeks were requested to voluntarily participate in the study by giving their consent to provide two sputum samples, one spot and one early morning. A short questionnaire was used to collect information about cell number, age, and sex, length of current stay in prison, history and treatment of tuberculosis from each inmate who consented to participate in the study. Each prison inmate who met the inclusion criterion of a cough of 2 or more week's duration was given a unique study number and labeled sputum containers.

The spot sputum sample was collected at the first visit and the morning sample on the following day. About 2 $\mathrm{ml}$ of domestic bleach was added to each of the sputum sample in the sample container. The sputum samples were transported to the laboratory and allowed to digest and sediment overnight. The supernatant was carefully decanted and smears were prepared on clean grease free glass slides. The smears were heat fixed and stained 
with Ziehl-Nelson staining techniques and examined by light microscopy.

\section{Results}

The median age of the inmates screened was 34 years (range 17 - 72 years). The mean age was 37.13 years. The majority of the inmates screened were males (88.46\%). The range of duration of stay in prison before the screening was one month to 9 years. Out of the 52 inmates screened, 7 (13.38\%) had a history of previous incarceration and 8 of the inmates (15.38\%) including the 7 inmates reported past history of TB with either complete or incomplete treatment. Only one of these was smear positive in this study and only one was currently on anti-tuberculosis treatment.

The distribution of prison inmates with AFB positive smears is shown in Table 1. Of the 52 inmates tested, 11 (21.15\%) were smear positive for AFB. The cases were concentrated in 5 prison wards namely ward D, E, G ward cell 2, I ward cell 2 and Female ward. Seven of the eleven prison inmates positive for AFB were found in $\mathrm{D}$ ward and $\mathrm{E}$ ward with 4 in $\mathrm{D}$ ward and 3 in $\mathrm{E}$ ward.

Table 2 shows cases of smear positive pulmonary tuberculosis among the prison inmates according to age groups. The highest number of inmates screened and the highest prevalence of sputum positive TB cases was found in the age group 25 - 34 years. The next age group, 35 - 44 years had the next highest number of prison

Table 1. Distribution of prison inmates with acid fast bacilli positive smears by prison cells.

\begin{tabular}{cccc}
\hline Prison Cell & No. in Prison Cell & No. Screened & No. (\%) Positive for AFB \\
\hline C ward & 44 & 4 & $0(0)$ \\
D ward & 52 & 13 & $3(23.08)$ \\
E ward & 52 & 11 & $4(36.36)$ \\
G ward 1 & 35 & 2 & $0(0)$ \\
G ward 2 & 36 & 3 & $1(33.33)$ \\
E \& IDH ward & 21 & 2 & $0(0)$ \\
H ward 1 & 41 & 1 & $0(0)$ \\
H ward 2 & 36 & 1 & $0(0)$ \\
I ward 1 & 39 & 4 & $0(0)$ \\
I ward 2 & 39 & 3 & $2(66.67)$ \\
I ward 3 & 35 & 3 & $0(0)$ \\
Female ward & 19 & 5 & $1(20)$ \\
Total & $\mathbf{4 4 9}$ & $\mathbf{5 2}(\mathbf{1 1 . 5 8 \% )}$ & $\mathbf{1 1}(\mathbf{2 1 . 1 5 \% )}$ \\
\hline
\end{tabular}

Table 2. Age distribution of smear positive cases among the prison inmates.

\begin{tabular}{cccc}
\hline Age group (Yr) & No. screened & No. (\%) positive for AFB & Proportion (\%) of the total (n= 52) \\
\hline $15-24$ & 6 & $1(16.67)$ & 1.92 \\
$25-34$ & 22 & $7(31.82)$ & 13.46 \\
$35-44$ & 15 & $2(13.33)$ & 3.85 \\
$45-54$ & 2 & $0(0)$ & 0 \\
$55-64$ & 6 & $0(0)$ & 1.92 \\
$>65$ & 1 & $1(100)$ & $\mathbf{2 1 . 1 5}$ \\
\hline
\end{tabular}


inmates with symptoms of TB but only two cases of sputum smear positive TB were detected in this age group. Pulmonary tuberculosis cases were concentrated among the younger age groups.

Table 3 presents the distribution of cases according to duration of stay in prison. Five of the TB cases had stayed in the prison for less than six months to 18 months while the remaining 6 cases had stayed from between 31 months to more than 48 months in prison. A total of 12 inmates including one on anti-tuberculosis treatment at Aba prison had pulmonary tuberculosis, giving a minimum point prevalence rate of 2405 cases per 100,000 inmates.

\section{Discussion}

During the period of this study, a total of 52 (10.90\%) of 477 prison inmates at Aba Federal prison had symptoms suggestive of pulmonary tuberculosis and their sputum samples were tested for the presence of acid fast bacilli (AFB). Eleven (21.15\%) of the 52 tested were positive for AFB. With one inmate on anti-TB treatment, the point prevalence rate of active TB was 2405 per 100,000 prison inmates. The high point prevalence rate of 2405 per 100,000 populations found in this study at Aba Federal prison is about 14 times higher than the prevalence rate of 171 per 100,000 in the general population of Nigeria [6]. This is in agreement with median prevalence rate of 3357 cases per 100,000 prison population reported for African Region [7].

The prevalence rate of 2227 per 100,000 of prison population in Dhaka Central Jail, Bangladesh [1] is similar to the point prevalence rate found in this study. High incidence of smear positive tuberculosis (5.8\%) was found at penal camp of Bouaké, Ivory Coast [5], similarly, Rao [4] reported a prevalence rate of active TB in jail population in Karachi that was 3.75 times higher than that of the general population. The consequences of high prevalence of TB in prisons are not limited to within the prisons [8]. TB from inmates could spread through visitors, prison staff and discharged inmates into the larger society thereby jeopardizing the TB control efforts in the general population [9].

The selection of the best screening methods and diagnostic algorithms remains an important consideration in the control of TB in prisons [7]. Lack of adequate laboratory or diagnostic facilities limits the implementation of guidelines for control of tuberculosis in prisons. In many settings, active-case detection is rarely done and this permits delay in detection of cases and lead to continued transmissions of TB in prisons.

In this study, active case finding detected 11 new cases of smear positive TB at Aba Federal Prison. Only one inmate detected through the usual passive case finding was on anti-TB treatment before this study. The result of this study therefore highlights the importance of active case finding of TB in prisons. A previous study at Aba prison employed a combination of Tuberculin skin test (TST), smear microscopy and culture, and a prevalence of 54.2\% was reported [10]. However, only 3 smear positive cases were reported in their study. In the present study, we employed bleach sedimentation method which had been reported to be more sensitive than the direct smear microscopy for detection of sputum smears [11]. Due to lack of facilities, we were unable to conduct

Table 3. Distribution of sputum positive cases by duration of stay in prison.

\begin{tabular}{|c|c|c|}
\hline Duration of stay (months) & No. (\%) screened & No. (\%) AFB positive \\
\hline$<6$ & 19 (36.54) & $1(5.26)$ \\
\hline $7-12$ & $5(9.62)$ & $2(40)$ \\
\hline $13-18$ & $5(9.62)$ & $2(40)$ \\
\hline $19-24$ & $3(5.77)$ & $0(0)$ \\
\hline $25-30$ & $0(0)$ & $0(0)$ \\
\hline $31-36$ & $2(3.85)$ & $1(50)$ \\
\hline $37-42$ & $3(5.77)$ & $1(33.33)$ \\
\hline $43-48$ & $5(9.62)$ & $2(40)$ \\
\hline$>48$ & $10(19.23)$ & $2(20)$ \\
\hline Total & $52(100)$ & $11(21.15)$ \\
\hline
\end{tabular}


sputum culture. Sputum culture might have detected more cases as the low sensitivity of sputum smear microscopy is well known [12].

The distribution of prison inmates with AFB positive smears was concentrated in 5 prison wards namely ward D, E, G ward cell 2, I ward cell 2 and Female ward. Seven of the eleven prison inmates positive for AFB were found in D ward and E ward with 4 in D ward and 3 in E ward. D ward, the convict cell, houses the prison inmates that had stayed in the prison for a periods ranging from few months to 9 years. E ward with other cells housed the prison inmates awaiting trial. Seven of the awaiting trial inmates were smear positive for AFB. While the smear positive prisoners with long jail terms can remain a source of long term transmission of TB in prison if untreated, the awaiting trial prisoners which come frequently in contact with the public during court appearances can constitute a source of risk of transmission of TB to the general public. Since the prisoners were not screened for TB at the time of admission, it was not clear whether those on awaiting trial list contracted TB in the prison or before coming to the prison. However, since some of the prisoners have only been in the prison for some few months, it is most probable that some might have contracted the disease before coming to the prison. This view was supported by the fact that one of the 19 prisoners who had stayed for six months or less was smears positive.

There is a need to urgently improve on the prison medical service, particularly as it relates to tuberculosis control in prison. The prison medical service should closely work with the National Tuberculosis Control Programme to ensure that prison inmates are regularly screened for TB. Those found positive should be promptly placed on treatment through the directly observed Treatment Short Course (DOTS) by linking them with the nearest DOTs Centre. New prison inmates should be screened before admission into the prison and any prisoner with TB should be properly followed up after release from prison to ensure completion of treatment [13]. Improvement in the general sanitation of the prison as well as the provision of adequate nutrition will also contribute to the efforts to control TB in the Nigerian Prisons.

\section{Acknowledgements}

We are grateful to the staff of Aba Federal Prison, Aba, for assistance. Dr. E. O Ekundayo acknowledges the TETFUND and Michael Okpara University of Agriculture, Umudike for funding part of this research.

\section{References}

[1] Banu, S., Hossaein, A., Uddin, M.K.M., Uddin, M.R. and Ahmed, T. (2010) Pulmonary Tuberculosis and Drug Resistance in Dhaka Central Jail, the Largest Prison in Bangladesh. PLoS One, 5, e10759. http://dx.doi.org/10.1371/journal.pone.0010759

[2] Lawal, M.A., Omili, M., Bello, T.O., Onuoha, L. and Haruna, A. (2009) Tuberculosis in Nigerian Medium Security Prison. Benin Journal of Postgraduate Medicine, 11, 3-7.

[3] Noeske, J., Kuaben, C., Amougou, G., Piubello, A. and Pouillot, R. (2006) Pulmonary Tuberculosis in the Central Prison of Douala, Cameroon. East African Medical Journal, 83, 25-30. http://dx.doi.org/10.4314/eamj.v83i1.9357

[4] Rao, N.A. (2004) Prevalence of Pulmonary Tuberculosis in Karachi Central Prison. Journal of Pakistan Medical Association, 54, 413-415.

[5] Koffi, N., Ngom, A.K., Aka-Danguy, E., Séka, A., Akoto, A. and Fadiga, D. (1997) Smear Positive Pulmonary Tuberculosis in a Prison Setting; Experience in the Penal Camp of Bonaké, Ivory Coast. International Journal of Tuberculosis and Lung Disease, 1, 250-253.

[6] World Health Organization (2012) Global Tuberculosis Report. WHO/HTM/TB/2012.6, Geneva. www.who.int/tb/data/Nigeria

[7] Vinkeles Melchers, N.V.S., van Elsland, S.L., Lange, M.A., Borgdorff, M.W. and van den Hombergh, J. (2013) State of Tuberculosis in Prison Facilities: A Systematic Review of Screening Practices and Recommendations for Best TB Control. PLoS One, 8, e53644.

[8] The PLoS Medicine Editors (2010) The Health Crisis of Tuberculosis in Prisons Extends beyond the Prison Walls. PLoS Medicine, 7, e1000383. http://dx.doi.org/10.1371/journal.pmed.1000383

[9] Baussano, I., Williams, B.G., Nunn, P., Beggiato, M., Fedeli, U. and Scano, F. (2010) Tuberculosis Incidence in Prisons: A Systematic Review. PLoS Medicine, 7, e1000381. http://dx.doi.org/10.1371/journal.pmed.1000381

[10] Chigbu, L.N. and Iroegbu, C.U. (2010) Incidence and Spread of Mycobacterium tuberculosis-Associated Infection among Aba Federal Prison Inmates in Nigeria. Journal of Health, Population and Nutrition, 28, 327-332. 
[11] Ongkhamny, S., Amstutz, V., Barennes, H. and Buisson, V. (2009) The Bleach Method Improves the Detection of Pulmonary Tuberculosis in Laos. International Journal of Tuberculosis and Lung Disease, 13, 1124-1129.

[12] Steingart, K.R., Ng, V., Henry, M., Laal, S., Hopewell, P.C., Ramsay, A., Cunningham, T., Urbanczik, R., Perkins, M.D., Aziz., Z.A. and Pai, M. (2006) Sputum Processing Methods to Improve the Sensitivity of Smear Microscopy for Tuberculosis: A Systematic Review. Lancet Infectious Disease, 6, 664-674. http://dx.doi.org/10.1016/S1473-3099(06)70602-8

[13] Nogueria, P.A., Abrahão Cabral de Melo, R.M. and Galesi, V.M.N. (2012) Tuberculosis and Latent Tuberculosis in Prison Inmates. Revista de Saúde Pública, 46, 119-127. http://dx.doi.org/10.1590/S0034-89102011005000080 